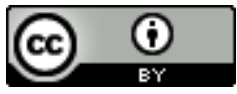

Esta obra está sob o direito de Licença Creative Commons Atribuição 4.0 Internacional.

\title{
A INFLUÊNCIA DO LETRAMENTO NA EDUCAÇÃO INFANTIL
}

\author{
Michelly Cristina Apolinário de Lucena ${ }^{1}$ \\ Cleidejane Soares de Barros ${ }^{2}$ \\ Betijane Soares de Barros ${ }^{3}$
}

\section{RESUMO}

O presente artigo traz como enfoque mostrar a influência do letramento no ensino infantil, sob uma perspectiva de melhorar o conhecimento da criança da pré-escola, através de pesquisa bibliográfica. A Educação Infantil tem sido alterada à medida que a criança passa a ser vista como sujeito de educação, com necessidade de atendimento qualificado. O objetivo do artigo é mostrar a presença do letramento na pré-escola e a capacidade dos pequenos em aprender desde cedo. A educação infantil ocupa claramente um lugar importante no desenvolvimento dessas crianças para a vida. "O artigo refaz um caminho no qual a infância e a criança são percebidas em sua dimensão singular", de modo a recuperar, no fim do percurso, em um caráter plural que as noções de criança e infância encerram. A principal contribuição deste artigo é apresentar encaminhamentos para amenizar as dificuldades das crianças no ensino infantil.

Palavras-chave: Letramento. Educação infantil. Escola.

\footnotetext{
1 michellyt_pc@hotmail.com.

2 dr.csb@hotmal.com.

3 bj-sb@hotmail.com.
} 


\section{INTRODUÇÃO}

Este artigo objetiva mostrar a influência do letramento no ensino infantil, é na pré-escola que as crianças das passam a integrar o mundo das letras. De fato, vivemos em um mundo de mudanças, de convívio entre diferentes gerações. Portanto, propõe uma escola sem coerção, na qual o aluno é convidado a experimentar ativamente, para reconstruir por si mesmo, aquilo que tem de aprender.

Conforme La Taille (1992), para Vygotsky, o sujeito não é apenas ativo, mas interativo, e forma os conhecimentos e se constitui a partir de relações no plano social, interpessoal, e no plano individual intrapessoal. É na relação consigo mesmo e com os outros sujeitos que ocorre a internalização dos conhecimentos. Então, as crianças elas não veem como uma folha em branco de casa, elas trazem muitas informações e cabe à escola organizar seus saberes.

A criança se insere, atualmente, no sistema educacional cada vez mais cedo. Muitas das mudanças referidas foram provocadas por uma maior participação feminina no mercado de trabalho, alterando a rotina de cuidados e a educação dos filhos. Esse fato é relacionado com a criação das creches. Nesse sentido, a creche estava sempre associada a um caráter assistencialista e se preocupava apenas com a alimentação, a higiene e a segurança física.

Portanto, o modelo de Educação Infantil tem sido alterado à medida que a concepção de educação da criança de 0 a 6 anos atinge objetivos diferenciados, com propostas educacionais explícitas fundamentadas em teorias psicológicas do desenvolvimento infantil. A criança nessa idade passa a ser vista como sujeito de educação, com necessidade de atendimento qualificado que vise o seu desenvolvimento integral sendo ela capaz de aprender. De acordo com Jobim e Souza (1995), é por meio da linguagem, juntando palavra e emoção que a criança não só anuncia o sonho e a esperança, como desvenda seus medos e aprimorar seus conhecimentos.

A criança constrói o seu desenvolvimento na interação com o meio em que vive, portanto, depende das condições desse meio, da vivência de objetos e situações que levem ao letramento da educação infantil.

Toda criança tem direito que assegurar acesso à educação e ao cuidado infantil de qualidade para todas as crianças é uma pré-condição importante para a melhoria do desenvolvimento educacional. A primeira infância abrange o período em que as bases do desenvolvimento são lançadas e deve ser percebida como o primeiro estágio de educação. 
Nas seções seguintes vamos mostrar a importância do letramento na educação infantil.

\section{MATERIAL E MÉTODOS}

O presente trabalho se desenvolveu por meio de uma revisão de literatura de natureza qualitativa. Para a produção desta pesquisa, inicialmente, foi estabelecida identificação do tema. Em seguida, no que se refere à segregação das fontes adquiridas foram utilizadas bases de dados online:

\section{RESULTADOS}

\section{A importância do letramento na alfabetização}

Letramento e alfabetização são processos distintos cada um com suas especificidades. Porém, ambos são indispensáveis quando se leva em consideração a aprendizagem da leitura e da escrita.

Letramento é o resultado da ação de ensinar ou de aprender a ler e escrever, foi na segunda metade dos anos 80 que surgiu o termo letramento em discursões feitas por especialistas em educação, segundo Magda Soares:

Letramento é o resultado da ação de ensinar e apreender as práticas sociais de leitura e escrita; é o estado ou condição que adquire um grupo social ou indivíduo como consequência de ter-se apropriado
BVS e Scielo. A fim de determinar as informações relevantes que seriam extraídas na revisão das fontes foram utilizadas como critérios de inclusão, artigos, monografias e teses na íntegra no idioma português, e como critério de exclusão os trabalhos que não eram gratuitos, os repetidos e os que não atendiam ao objetivo da pesquisa.

da escrita e de suas práticas sociais (SOARES, 1998).

Trata-se, portanto, de um processo que tem início quando a criança começa a conviver com as diferentes amostras de escrita na sociedade (rótulos, placas, entre outros), e se prolonga por toda a vida da criança e com o passar d tempo elas vão se aprimorando com o mundo letrado.

O conceito de alfabetização, por muito tempo, ficou atrelado à ideia de que para aprender a ler era necessária apenas a capacidade de decodificar. De acordo com Cagliari:
O processo de alfabetização inclui muitos fatores e, quanto mais ciente estiver o professor de como se dá o processo de aquisição de conhecimento, de como uma criança se situa em termos de desenvolvimento emocional, de como vem evoluindo o seu 
processo de interação social, da natureza da realidade linguística envolvida no momento em que está acontecendo a alfabetização, mais condições terá esse professor de encaminhar de forma agradável e produtiva $\mathrm{o}$ processo de aprendizagem, sem os sofrimentos habituais (CAGLIARI, 1998).

Reconhecendo a especificidade de cada um desses processos, é preciso combinar a alfabetização e o letramento, assegurando as crianças tanto a apropriação do sistema de escrita, como o domínio das práticas sociais de leitura e escrita. A diferença entre o alfabetizado e o letrado é que:

[...] um indivíduo alfabetizado não é necessariamente um indivíduo letrado; o alfabetizado é aquele indivíduo que sabe ler e escrever, já o indivíduo letrado, o indivíduo que vive um estado de letramento, é não só aquele que sabe ler e escrever, mas aquele que usa socialmente a leitura e a escrita, pratica a leitura e a escrita, responde adequadamente as demandas sociais e de escrita (SOARES, 2000, p. 39.).

Como consequência, o desafio que se coloca é "alfabetizando letrando", ou seja, possibilitar que a alfabetização se desenvolva em um ambiente onde a criança conviva com variados portadores que leve esse processo as crianças da educação infantil.

\section{Letramento $x$ educação infantil $x$ família}

Em nossa sociedade, todo cidadão, qualquer que seja seu grau de escolaridade ou posição social, está imerso no mundo letrado, assim como a criança que ingressa na escola precisamente na educação infantil ainda não alfabetizado, já faz parte do mundo da escrita e do letramento.

Daí a importância de se perceber a sala de aula como um espaço que possa promover tanto o domínio de capacidades de se alfabetizar letrando, desde a educação infantil como um espaço gerador de saúde mental e física, de conforto e desenvolvimento pleno da criança, desde a creche.

De acordo com Goldschmied (2006), "as instituições de educação infantil podem incluir ou não a família no planejamento de seus serviços". A posição adotada determinará o tipo de relação dos pais com os educadores infantis. Garantir as crianças o direito de acesso à educação infantil implica considerar a família como base afetiva e de referência primária à sua individualidade e socialização das crianças da pré-escola.

Para que a exploração e experimentação do letramento aconteçam de forma positiva, torna-se necessário passar pelos “erros" próprios do conhecimento. Esses erros construtivos, que são as formas criadas pela própria criança, 
quando confrontada com as experiências convencionais. Esse processo precisa ser, portanto, ao mesmo tempo prazeroso e instigante para os pequeninos.

Segundo Charner (2012), "no meio natural, a criança aprende melhor sobre os recursos naturais e a importância da preservação, desenvolve mecanismos de percepção e torna-se mais atenta aos processos de ensino-aprendizagem", e a partir desses fatores as crianças se inserem no mundo do letramento com suas descobertas e curiosidades. Trabalhando com o lúdico através de (teatro e música), facilita as crianças da educação infantil fazer parte do letramento. O Referencial Curricular para a Educação Infantil reconhece que:

Em todas as culturas as crianças brincam com a música. Jogos e brinquedos musicais são transmitidos por tradição oral, persistindo nas sociedades urbanas nas quais a força da cultura de massa é muito intensa, pois são fontes de vivências e desenvolvimento expressivo musical. Envolvendo o gesto, o movimento, o canto, a dança, e o faz-de-conta, esses jogos e brincadeiras são expressão da infância (BRASIL, 1998, v.3, p.71-72).

Assim, a aprendizagem musical deve levar em consideração um fazer em que estejam presentes a criação, a invenção, a imitação, a improvisação e as diferentes formas de se expressar através do som, possibilitando o desenvolvimento da capacidade de observar, de reconhecer e de espirito crítico.

Portanto, quando as crianças da educação infantil começam a frequentar a escola ela já se inseri no mundo letrado ainda que seja através de símbolos e desenhos onde os pequenos trazem conhecimento da sua casa.

\section{Contribuições do letramento na educação infantil}

No entanto, é na escola que se adquire o domínio da língua oral e escrita e no caso das crianças precisam de um cuidado todo especial. A criança de 4 anos que ingressa na escola acha-se bruscamente confrontada com uma situação nova á qual terá de adaptar-se rapidamente. Os problemas com os quais ele vai envolver-se implicam, em muitos casos em encontrar com pessoas não conhecidas antes e hábitos trazidos de casa.

De acordo com Vieira (2012), "é preciso que a escola perceba que os alunos têm vida própria, têm histórias de vida, vivem numa sociedade e em cultura especificas e, portanto não se apaga quando os alunos entram na escola", ninguém aprende no vazio, as pessoas aprendem comparando o que já sabem com a novidade e, portanto, a aprendizagem ocorre sempre, de alguma forma, em resultado de uma mediação relativamente ao seu modo de 
ver, aos seus conhecimentos, a sua leitura do mundo.

A situação da criança se torna ainda mais difícil pôr as exigências por parte dos pais que quando os filhos não acompanham o nível das outras crianças na aprendizagem, por que antes de tudo as crianças precisam de afetividade e que elas têm que aprender através do lúdico.

Como Paulo Freire escreveu, tratase de "uma educação para a libertação", de uma educação de sujeitos. De uma educação global. É nesse tipo de educação a escola tem de preparar para a convivência, para aprendê-lo a viver com os outros (JARES, 2007).

As vivências infantis em relação ao brincar, as experiências escolares com alguma conotação lúdica, as oportunidades de aprender na interação com os outros coleguinhas, ainda durante a formação inicial, com crianças em situação lúdica, a relação positiva com a própria aprendizagem e para isso os educadores tem que ser dedicados e amorosos com as crianças, Jaume (2004) destaca, entre tais necessidades, aquelas que dizem respeito aspectos como afetividade, autonomia, movimento, socialização, descoberta, exploração e conhecimento.

Desde o início da sua trajetória escolar a criança tem que desenvolver o gosto por a leitura e que a escrita também tem que caminhar junto. $\mathrm{O}$ problema que então se coloca é o de determinar e este insucesso surge de dificuldades eletivas ou de causas mais globais socioculturais ou afetivas. Entretanto, não se deve se descuidara importância das pressões culturais e seu papel na criação de uma forte motivação na criança. Daí a importância do investimento familiar na escolaridade de um indivíduo.

A escrita, como a linguagem é essencialmente um modo de expressão e de comunicação. Entretanto, a linguagem é anterior ao grafismo e o aprendizado da leitura e da escrita apoia-se numa linguagem expressiva em cujo nível a sucessão sonora e a qualidade dos sons emitidos não manifestem déficit patente. (BOULCH, 2010, p. 31).

O desenho começa como uma escrita e a escrita como um desenho. Com o tempo, a criança cria formas de diferenciação entre um e outro. $\mathrm{O}$ desenho favorece a expressão de uma ideia, contribui para a construção da escrita, pode ser um mediador entre o eu da criança e o mundo.

Isso acontece porque, segundo Tolchinsky (1995), as crianças, ao utilizarem o desenho como meio de notação, fazem-no porque se aproveitam dos diversos recursos disponíveis para a representação de uma história, e não porque confundem aas duas formas de registro. Por isso podemos garantir que também nossas 
práticas vão sendo alteradas em função dessas vivências e de novas compreensões sobre como alfabetizar e de como letra as crianças da educação infantil.

Dessa forma, a apropriação da leitura e da escrita leva a criança a formular hipóteses e a enfrentar contradições e diferenças entre sua construção pessoal e a

\section{CONCLUSÃO}

No entanto, foi visto que é de suma importância a presença do letramento no ensino infantil. A educação se baseia necessariamente na garantia do direito à educação de qualidade para todos inclusive as crianças. Pôde-se constatar a importância da pré-escola no desenvolvimento intelectual.

A educação infantil é chamada a responder às necessidades decorrentes da diversidade dos mundos em que vivem as crianças. Talvez, o ensino infantil não aprenda suficientemente com as crianças esse jeito de olhar e meter os dedos para tirar a figura com que se desenha a vida, e nota-se que o letramento já se faz presente na pré-escola.

São tantos os desafios enfrentados pela instituição de ensino infantil, não é nada fácil educar e educar crianças principalmente. Com tudo em educação, não há respostas prontas mais ideias e propostas que podem sugerir alternativas escrita alfabética que encontra em seu ambiente escolar, comunitário e letrado. A construção desse conhecimento não é fácil, nem tão pouco simples, trata-se de uma aprendizagem complexa, individual e subjetiva, mas não solitária, porque exige, ao mesmo tempo, trocam de informações, estímulos e motivação.

que iram contribuir com a prática na préescola.

A escola se apresenta como direcionadora e informadora diante das adversidades da vida educacional, que continua mesmo fora da escola. Sendo assim, esse é um modelo educacional muito interessante para ser estudado a fim de que possa gerar ideias e subsídios não apenas para o seu aperfeiçoamento, mas, principalmente, contribuir para a construção de novas propostas para a educação infantil nas escolas públicas do País para com isso diminui as dificuldades do ensino-aprendizagem mostrando que a criança desde cedo já é capaz de fazer suas interpretações e tirar suas conclusões.

A discussão de uma educação para os direitos humanos deve destacar a necessidade de implantação de projetos que iram auxiliar o ensino na pré-escola, e com isso melhorar a aprendizagem das crianças.

É com estas considerações acima que vivemos em momento de grande inspiração literária entregando-se a uma 
nova época que envolve a educação infantil

e a valorização da mesma em nossas

escolas.

\section{REFERENCIAS}

BOULCH, Le Jean. Educação

Psicomotora. Porto Alegre: Artmed, 1987.

BRASIL. Referencial Curricular para a

Educação Infantil. Ministério da Educação e do Desporto, Secretaria de Educação Fundamental-Brasília: MEC/SEF, 1998. V. 1: Documento Introdutório; v.2 Formação Pessoal e Social; v. 3: Conhecimento de mundo.

CAGLIARI, Gladys; CAGLIARI, Luís Carlos. Alfabetização sem o babebibobu. São Paulo: Scipione, 1998.

CHARNER, K. Nosso planejamento verde: 100 ótimas propostas para trabalhar na educação infantil. Porto Alegre: Penso 2012.

GOLDSCHMIED, E. Jackson, S. Educação d 0 a 3 anos. Porto Alegre: Artmed, 2006.

JAUME, M.A In: ARRIBAS T. Educação Infantil. Porto Alegre: Artmed, 2004.

JARES, Xesus. Rodrigues. Pedagogia da convivência, Porto: Profedições, 2007.

SOARES b, Magda. Alfabetização e letramento: um tema em três gêneros. Belo Horizonte: Autêntica, 1998.

Letramento: um tema em três gêneros. Belo Horizonte: Autêntica, 2000.

SOUZA, S. J. Infância e linguagem: Bakhtin, Vygotsky e Benjamim. 2. Ed. Campinas, SP: Papirus, 1995.

TOLCHINSKY, L. L. Aprendizagem da linguagem escrita- processos evolutivos e implicações didáticas. São Paulo: Ática, 1995.

VIEIRA, Ana. A Mediação Escolar. Presença Pedagógica, v. 18, n. 105, mai./jun., 20012. 